CLINICAL STUDY

\title{
High penetrance of pheochromocytoma in multiple endocrine neoplasia 2 caused by germ line RET codon 634 mutation in Japanese patients
}

Tsuneo Imai, Shinya Uchino ${ }^{1}$, Takahiro Okamoto $^{2}$, Shinichi Suzuki $^{3}$, Shinji Kosugi ${ }^{4}$, Toyone Kikumori $^{5}$, Akihiro Sakurai ${ }^{6}$ and MEN Consortium of Japan

Division of Breast and Endocrine Surgery, Department of Surgery, Aichi Medical University, 1-1 Karimata, Yazako, Nagakute, Aichi 480-1195, Japan, ${ }^{1}$ Noguchi Thyroid Clinic and Hospital Foundation, Beppu 874-0932, Japan, ${ }^{2}$ Department of Endocrine Surgery, Tokyo Women's Medical University, Tokyo 162-8666, Japan, ${ }^{3}$ Department of Breast, Endocrine, and Thyroid Surgery, Fukushima Medical University, Fukushima 960-1295, Japan, ${ }^{4}$ Department of Medical Ethics/Medical Genetics, Kyoto University School of Public Health, Kyoto 606-8501, Japan, ${ }^{5}$ Department of Breast and Endocrine Surgery, Nagoya University, Nagoya 466-8550, Japan and ${ }^{6}$ Department of Medical Genetics, Shinshu University School of Medicine, Matsumoto 390-8621, Japan

(Correspondence should be addressed to T Imai; Email: timai@med.nagoya-u.ac.jp)

\begin{abstract}
Objective: The precise penetrance of pheochromocytoma (PHEO) in multiple endocrine neoplasia type 2 (MEN2) has not been reported in a large cohort. In this study, we aimed to clarify the codon-specific penetrance of PHEO in MEN2.

Design: We established a study group designated the 'MEN Consortium of Japan' in 2008 and asked physicians and surgeons to provide clinical and genetic information on patients they had treated up to 2011. Methods: Data were collected on patients identified as carriers of the RET mutation or diagnosed with medullary thyroid carcinoma (MTC) and/or PHEO with family history from 52 institutions all over Japan. Results: Of 493 registered MEN2 patients, RET mutation data were available for 390. Of these, 144 developed PHEOs, while 246 did not. The penetrance of PHEO was $25 \%$ by age 30 years, $52 \%$ by age 50 years, and $88 \%$ by age 77 years in RET mutation carriers with a codon 634 mutation. All patients with a codon 918 mutation (MEN2B) developed PHEO by age 56 years. Less than $32 \%$ penetrance of PHEO was seen in patients with mutations at codons other than 634 and 918. Conclusions: Most patients with a codon 634 mutation develop PHEOs as well as MTC during their lifetime.
\end{abstract}

European Journal of Endocrinology 168 683-687

\section{Introduction}

Multiple endocrine neoplasia type 2 (MEN2) is an autosomal dominantly inherited endocrine tumor syndrome characterized by tumor development in various endocrine organs such as the thyroid, adrenal medulla, and parathyroid (1). It is commonly accepted that $\sim 50 \%$ of patients with MEN2 develop pheochromocytoma (PHEO) during their lifetime $(2,3)$. Before the development of genetic screening, diagnosis of MEN2 was mainly clinical. As the advent of RET mutation diagnosis, genotype-phenotype relationships have affected clinical management $(4,5)$. Specific agerelated neoplastic risk profiles and penetrance estimations of PHEO have been reported in MEN2A caused by germ line RET mutations in C634W, C634Y/Y791F, and C609S $(6,7,8)$. Precise codon-specific development of PHEO has been reported, although no figures on penetrance were provided (9). Analysis of organ-specific penetrance demonstrated that PHEO penetrance occurred in the majority of cases with mutations at codon 634 and 918, but in only a minority of cases with mutations at codons 618 and 620, and was rarely associated with other mutations (5). However, detailed figures for penetrance at each codon were not provided.

To date, reports concerning MEN2 PHEO have mainly originated from Europe and the United States, and the guidelines and consensus statements have been based on those studies $(4,5,9,10)$. Some reported a founder effect in the particular country (11). We established a study group designated the 'MEN Consortium of Japan' in 2008 (12) and started constructing a database of Japanese patients with MEN, asking physicians and surgeons to provide clinical and genetic information on patients they had treated up to 2011. RET mutation data were available in 390 MEN2 patients, 144 of whom developed PHEO, while 246 did not. Herein, we report the characteristics of Japanese MEN2 PHEO patients and the current status of their clinical management, with particular emphasis on data elucidating the penetrance of PHEO at each codon, and we report 
high penetrance of PHEO resulting from the RET 634 mutation in Japanese patients. Although the specific effects of different amino acid substitutions at codon 634 differed between Japanese and European/American cohorts, the overall penetrance of PHEO was very similar.

\section{Materials and methods}

\section{Patients}

The MEN Consortium of Japan began as a private study group not regulated by any academic society. In 2008, physicians and surgeons from 15 institutions joined the Consortium and the number of members had reached 27 by May, 2011. The detailed methods used to collect the data have been reported elsewhere (12). Briefly, we prepared a registration form to record patient data, with the required data including gender, birth date, family history, proband or not, the dates when each lesion was detected, medical and surgical management of all lesions and their outcome, and both pathological and genetic information. To facilitate registration of patients from institutions not belonging to the Consortium, we sent letters to 1376 members of the Japan Association of Endocrine Surgeons, Japanese Society of Thyroid Surgery, and board of representatives of the Japan Endocrine Society, asking these physicians to report the number of patients with MEN2 in their experience (initial surveillance). When a reply was received, we sent the aforementioned questionnaire asking for detailed information on patients (secondary surveillance). With particular regard to MEN2 PHEO, the following specific questions were included: i) was there a positive diagnosis of PHEO? If yes, age at diagnosis. ii) Was surgical intervention performed? If yes, age at surgery. iii) Was there unilateral or bilateral involvement? iv) Which particular surgical procedures were performed? v) Was there a malignant feature with metastatic PHEO? vi) Were multiple surgeries performed? vii) Was genetic testing performed? viii) Is the patient alive? This study was approved by the Institutional Review Board of Shinshu University School of Medicine.

\section{Clinical data}

Because of the retrospective design, the diagnostic criteria for MEN2 may have varied between hospitals. At least one of the following criteria had to be present for inclusion in the registry:

- Combination of medullary thyroid carcinoma (MTC) and PHEO.

- Evidence of one lesion of MTC or PHEO with a family history of MEN2.

- Identification of pathological germ line mutation in the RET gene.

The selected patients' data were deposited into the database. Possible inconsistencies and missing data were validated and corrected if appropriate. To avoid duplicate registration of a single patient, those with the same sex and birth date were reviewed to determine whether such reports were for the same patient. In total, 52 institutions provided the eligible data on MEN2 patients.

The screening examinations depended on the institutions where the patients were assessed, but determination of the absence of PHEO was based on measurements of urinary metanephrine and normetanephrine per mg creatinine levels as a minimum (13). To calculate the penetrance of PHEO in MEN2, the index cases for each family were excluded from the calculation.

\section{Statistical analyses}

We estimated age-dependent penetrance for PHEO by the Kaplan-Meier method using JMP ver. 9. Differences in the occurrence of PHEO were calculated by generalized Wilcoxon $\chi^{2}$ statistics across groups. $P<0.05$ was considered significant.

\section{Results}

\section{Patient demographics}

As of May 2011, of 493 registered MEN2 patients, RET mutation data were available for 390, and 212 of the 493 had PHEOs. The cohort consisted of 85 men and 127 women belonging to 160 kindreds. The occurrence of PHEO was bilateral in 117 patients and unilateral in 73 patients. Open abdominal adrenalectomy was performed in 52 patients, open retroperitoneal adrenalectomy in 34, and laparoscopic adrenalectomy in 48 . Pathological diagnosis confirmed PHEO in all patients, and two cases (1\%) were metastatic and diagnosed as malignant PHEO. These demographic features are shown in Table 1. The median age at diagnosis of PHEO was 39 years old, with major peaks in the 20s and 40s. PHEO diagnosis was made after the diagnosis of MTC in 71 patients $(34 \%)$, simultaneously in 102 patients $(49 \%)$, and before the diagnosis of MTC in 37 patients (17\%).

Adrenal surgery was performed on 181 of the 212 patients $(88 \%)$. There was no information regarding whether surgery was performed or not in six patients, while the other four patients underwent adrenalectomy but the detailed procedures were not reported. Adrenalectomy was unilateral in 73 patients and bilateral in 104 (one stage in 71 and two stage in 33). Seventeen of the 181 patients underwent cortical sparing adrenalectomy. Surgery has not been indicated so far in 25 patients, in whom PHEO sizes remained small with most tumors being less than $2 \mathrm{~cm}$ without any symptoms.

Mortality was 12\% (25 of 212) among MEN2 PHEO patients, and the causes of death were classified into three categories: MTC, PHEO, or other causes (Table 1). Of these categories, six patients died from PHEO (proband: 1; RET mutation carriers: 4; unknown: 1), and death from PHEO was associated with the youngest median age 
Table 1 Demographic and disease characteristics of 212 PHEO patients with MEN2.

\begin{tabular}{lc}
\hline & No. of patients \\
\hline Men & 85 \\
Women & 127 \\
Total & 212 \\
Treatment of PHEO & \\
Bilateral adrenalectomy & 104 \\
One stage & 71 \\
Two stage & 33 \\
Unilateral adrenalectomy & 73 \\
No surgery & 25 \\
Unknown & 10 \\
Total & 212 \\
Cause of death & \\
MTC & $14(53)^{\mathrm{a}}$ \\
PHEO & $6(39)^{\mathrm{a}}$ \\
Other than MEN2 & $4(60)$ \\
Unknown & 1 \\
Total & 25 \\
\hline
\end{tabular}

${ }^{\mathrm{a}}$ Median age of death is shown in parentheses (years).

of death (39 years old). No deaths occurred due to Addisonian crisis after bilateral total adrenalectomy.

\section{Codon-specific occurrence of PHEO}

The distribution of mutated RET codons in 390 patients with MEN2 is shown in Table 2. Codon 634 mutation accounted for $76 \%$ of the patients. The earliest adrenalectomies for PHEO were performed at 15 years of age in patients with codon 634 or 918 mutations and 16 years in patients with codon 620 mutation. The average age at diagnosis was 30.3 years for those with mutations at codon 918, 39.8 years for codon 634 , and 44.1 years for other codons. Those with codon 634 or 918 mutations had a higher risk of developing PHEO (more than 60\%), whereas those with other mutations had a lower risk (up to 17\%), in accordance with the American Thyroid Association (ATA) risk level (Table 2) (5).

\section{Penetrance}

To calculate the penetrance of PHEO in MEN2, the age at diagnosis when $\mathrm{PHEO}$ was detected, or the latest age at which PHEO was not detected, was determined for each RET mutation carrier. Excluding the probands, 246 RET mutation carriers were eligible, of whom 74 had PHEO and 172 did not. Age-dependent penetrance of PHEO in all RET mutation carriers was $32 \%$ by age 50 and $50 \%$ by age 76 (Fig. 1). PHEO penetrance for codon 634 mutation was $25 \%$ by age 30 years, $52 \%$ by age 50 years, and $88 \%$ by age 77 years. Age-dependent penetrance for mutations at other codons was $25 \%$ by age 50 years for codon $611,24 \%$ by age 52 years for codon $620,12.5 \%$ by age 54 years for codon 768 , and $12 \%$ by age 45 years for codon 618 . Most of the patients with codon 918 mutation were probands, and all these had developed PHEO by age 56 years.

Five different amino acid substitution mutations were identified at codon 634, which codes for cysteine. The number of patients carrying each mutation were: C634R: 39, C634Y: 33, C634F: 25, C634G: 11, and C634S: 4. Among these, C634R showed the highest penetrance (Fig. 2). There were statistically significant differences between C634R and C634G/C634F (P<0.01), but not between C634R and C634Y/C634S.

\section{Discussion}

The penetrance of PHEO due to codon 634 mutation was $25 \%$ by age 30 years and increased steadily with age up

Table 2 Position of mutated codon and age at first PHEO diagnosis in 144 patients with MEN2.

\begin{tabular}{|c|c|c|c|c|c|c|}
\hline & \multicolumn{2}{|c|}{ ATA risk level ${ }^{\mathrm{a}}$} & \multicolumn{2}{|c|}{ PHEO } & \multirow{2}{*}{$\begin{array}{l}\text { Percentage } \\
\text { of PHEO }\end{array}$} & \multirow{2}{*}{$\begin{array}{c}\text { Age at first PHEO diag } \\
\text { nosis (years) }\end{array}$} \\
\hline & MTC & PHEO & Yes (\%) & No (\%) & & \\
\hline 609 & $\mathrm{~B}$ & $\mathrm{R}$ & $1(0.7)$ & $5(2.0)$ & 16.7 & 50 \\
\hline 610 & & & $1(0.7)$ & $0(0.0)$ & 100.0 & 30 \\
\hline 611 & B & $\mathrm{R}$ & $4(2.8)$ & $20(8.1)$ & 16.7 & 42 \\
\hline 618 & B & MI & $8(5.6)$ & 60 (24.4) & 11.8 & 28 \\
\hline 620 & B & MI & $5(3.5)$ & 34 (13.8) & 12.8 & 16 \\
\hline 630 & B & $\mathrm{R}$ & $0(0.0)$ & $11(4.5)$ & 0.0 & \\
\hline 634 & C & MA & $110(76.4)$ & 68 (27.6) & 61.8 & 15 \\
\hline 661 & & & $0(0.0)$ & $1(0.4)$ & 0.0 & \\
\hline $697 / 825$ & & & $1(0.7)$ & $0(0.0)$ & 100.0 & 54 \\
\hline 768 & A & $\mathrm{R}$ & $1(0.7)$ & 18 (7.3) & 5.3 & 54 \\
\hline 778 & & & $0(0.0)$ & $1(0.4)$ & 0.0 & \\
\hline 790 & A & R/MI & $0(0.0)$ & $1(0.4)$ & 0.0 & \\
\hline 804 & A & $\mathrm{R}$ & $0(0.0)$ & $12(4.9)$ & 0.0 & \\
\hline 891 & $A$ & $\mathrm{R}$ & $0(0.0)$ & $10(4.1)$ & 0.0 & \\
\hline 918 & D & MA & $13(9.0)$ & $5(2.0)$ & 72.2 & 15 \\
\hline Total & & & 144 & 246 & 36.9 & \\
\hline
\end{tabular}

MTC, level D is highest risk; PHEO, MA, majority; MI, minority; R, rare.

${ }^{a}$ American Thyroid Association risk level. 


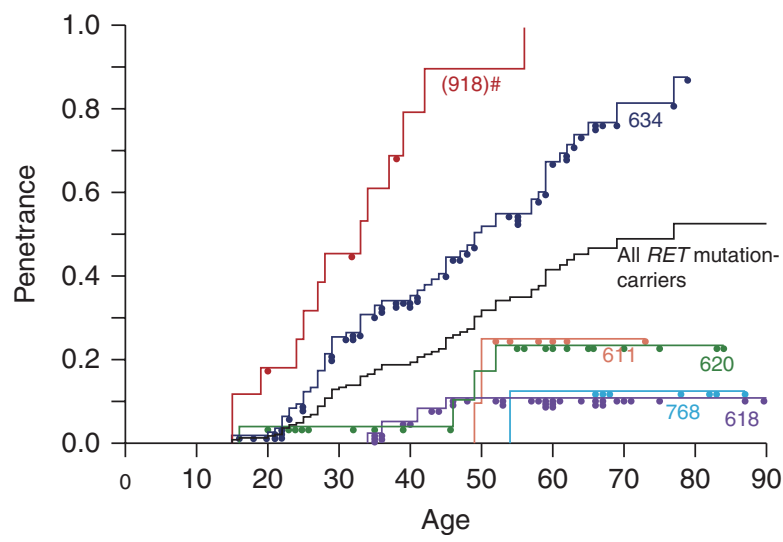

Figure 1 Codon-specific penetrance of PHEO in RET mutationcarrying Japanese MEN2 patients. Dots represent censored patients. \#: codon 918 includes probands. Full colour version of this figure available via http://dx.doi.org/101530/EJE-12-1106.

to $88 \%$ by age 77 years in RET mutation carriers residing in Japan (Fig. 1). Codon 611, 618, 620, and 768 mutations showed lower penetrance (below 32\%) for PHEO compared with codon 634 mutation, which is in accordance with the ATA risk level (5). The penetrance of MTC is considered to be almost $100 \%$ in patients with MEN2; however, that of PHEO has not been reported in a large cohort. Our results indicate that lifelong close follow-up for development of PHEO is necessary especially in patients with a codon 634 mutation.

C634R was the most common mutation at codon 634 in this study, in accordance with previously reported data $(14,15)$. High penetrance of PHEO was reported in 92 carriers with a $\mathrm{C} 634 \mathrm{~W}$ mutation from Europe and America: $20 \%$ by age 30 years and $67 \%$ by age 50 years, reaching $92 \%$ by age 70 years (6). We did not find any patient with a C634W mutation

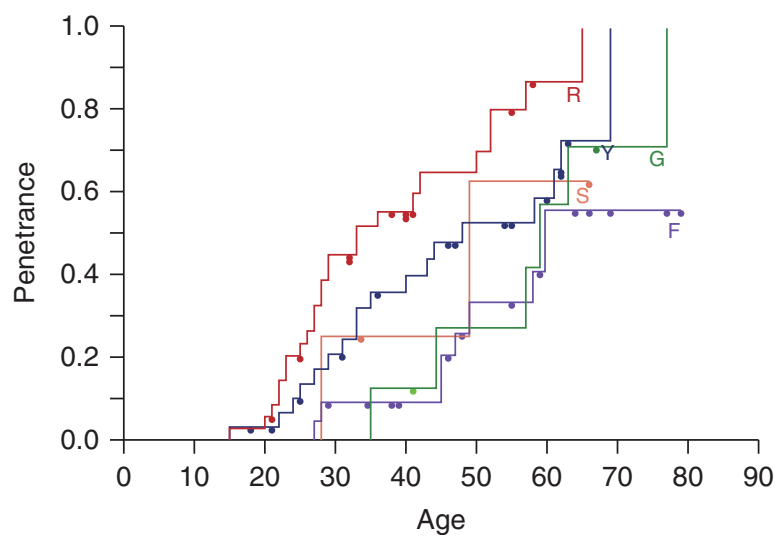

Figure 2 Amino acid-specific penetrance of PHEO in RET mutationcarrying Japanese MEN2 patients with mutations at RET codon 634. Dots represent censored patients. R: C634R (arginine), Y: C634Y (tyrosine), G: C634G (glycine), F: C634F (phenylalanine), and S: C634S (serine). Full colour version of this figure available via http://dx.doi.org/101530/EJE-12-1106. in Japanese MEN2A, but the penetrance of PHEO at codon 634 in Japan was very similar to that of the C634W mutation in Europe and America.

Codon-specific, age-dependent penetrance for PHEO was $25 \%$ by age 50 years at codon $611,24 \%$ by age 52 years at codon $620,12.5 \%$ by age 54 years at codon 768 , and $12 \%$ by age 45 years at codon 618. Higher penetrance was reported for those mutations located in exon 10 (codon 609, 611, 618, and 620) from Europe and America (16). No PHEO developed after the age of 54 years in Japanese patients with mutations located in exon 10 or codon 768 . On the other hand, penetrance of PHEO increased to $>60 \%$ by age 70 years in patients from 15 countries in Europe and America with codon 609, 611, 618, and 620 mutations (16). Overall penetrance and occurrence were very similar between Japan and Europe/America, but the individual figures showed racial and geographic differences between the populations.

MEN2 patients have the potential to develop bilateral adrenal PHEO, and surgical management remains controversial. Prophylactic total adrenalectomy is never performed because it commits the patient to lifelong steroid hormone replacement and the risk of a life-threatening Addisonian crisis. Partial adrenalectomy, so-called 'cortical sparing adrenalectomy,' has been proposed for the treatment of bilateral adrenal PHEO while maintaining adrenocortical function (17). However, the long-term outcomes of partial adrenalectomy in patients with MEN2 are not yet established (18). Only 17 of the 181 surgical patients in our series underwent cortical-sparing adrenalectomy.

MTC was previously the major cause of death in patients with MEN2; however, early thyroidectomy has lowered mortality from hereditary MTC (5). It is also probable that improved management of PHEO has reduced the rate of premature mortality in patients with MEN2. The median age of death among patients in this study who died of PHEO was 39 years old. Proper screening and management of PHEO promises to extend the life expectancy of MEN2 patients.

In the literature, over a mean follow-up period of 14 years (range 1-26 years), nine (32\%) of 28 patients who underwent bilateral adrenalectomy had a total of 19 Addisonian crises that necessitated admission to hospital, and one patient died of an unrecognized Addisonian crisis (19). In our series, adrenalectomy was unilateral in 73 patients and bilateral in 104 (one stage in 71 and two stage in 33). There were no reports of death from Addisonian crisis in the 104 patients, although most of the patients underwent bilateral total adrenalectomy. However, in a few cases, the description of the cause of death was inadequate, and it is possible that we may have missed some mortality due to an Addisonian crisis.

Collection and analysis of clinical information makes it possible to understand the clinical features of rare diseases and to standardize their medical management. In this regard, our database is a potentially powerful tool 
for improving the future management of MEN2 in Japanese patients. Although we are currently collecting only descriptive information, adding other data such as details of symptoms, imaging studies, and biochemical assays will further enhance the value of the database.

\section{Conclusions}

Most patients with a codon 634 mutation develop PHEOs as well as MTC during their lifetime.

\section{Declaration of interest}

The authors declare that there is no conflict of interest that could be perceived as prejudicing the impartiality of the research reported.

\section{Funding}

This study was supported by a Grant from the Japanese Government Ministry of Health, Welfare and Labor (H24-Nanchi-Ippan-053 to A Sakurai).

\section{Acknowledgements}

The authors acknowledge the coauthors: Toshihiko Fukushima, Kazuhiro Hanazaki, Shohei Hirakawa, Takehito Igarashi, Tsuguo Iwatani, Makoto Kammori, Takuyuki Katabami, Miyuki Katai, Kazuyo Kiribayashi, Shigeki Koizumi, Sanae Midorikawa, Rika Miyabe, Takuya Munekage, Atsushi Ozawa, Kazuo Shimizu, Iwao Sugitani, Hiroshi Takeyama, and Masanori Yamazaki. This activity of the consortium has been selected as one of the 'high-profile clinical issues' of the Japan Endocrine Society.

\section{References}

1 Carney JA, Sizemore GW \& Hayles AB. Multiple endocrine neoplasia, type 2b. Pathobiology Annual $1978 \mathbf{8} 105-153$.

2 Casanova S, Rosenberg-Bourgin M, Farkas D, Calmettes C, Feingold N, Heshmati HM, Cohen R, Conte-Devolx B, Guillausseau PJ, Houdent C et al. Phaeochromocytoma in multiple endocrine neoplasia type 2 A: survey of 100 cases. Clinical Endocrinology $1993 \mathbf{3 8}$ 531-537. (doi:10.1111/j.1365-2265. 1993.tb00350.x)

3 Modigliani E, Vasen HM, Raue K, Dralle H, Frilling A, Gheri RG, Brandi ML, Limbert E, Niederle B, Forgas L et al. Pheochromocytoma in multiple endocrine neoplasia type 2: European study. The Euromen Study Group. Journal of Internal Medicine 1995238 363-367. (doi:10.1111/j.1365-2796.1995.tb01211.x)

4 Brandi ML, Gagel RF, Angeli A, Bilezikian JP, Beck-Peccoz P, Bordi C, Conte-Devolx B, Falchetti A, Gheri RG, Libroia A et al. Guidelines for diagnosis and therapy of MEN type 1 and type 2. Journal of Clinical Endocrinology and Metabolism 200186 5658-5671. (doi:10.1210/jc.86.12.5658)

5 American Thyroid Association Guidelines Task F, Kloos RT, Eng C, Evans DB, Francis GL, Gagel RF, Gharib H, Moley JF, Pacini F, Ringel MD et al. Medullary thyroid cancer: management guidelines of the American Thyroid Association. Thyroid 200919 565-612. (doi:10.1089/thy.2008.0403)

6 Milos IN, Frank-Raue K, Wohllk N, Maia AL, Pusiol E, Patocs A, Robledo M, Biarnes J, Barontini M, Links TP et al. Age-related neoplastic risk profiles and penetrance estimations in multiple endocrine neoplasia type $2 \mathrm{~A}$ caused by germ line RET Cys634Trp (TGC $>$ TGG) mutation. Endocrine-Related Cancer 200815 1035-1041. (doi:10.1677/ERC-08-0105)

7 Kinlaw WB, Scott SM, Maue RA, Memoli VA, Harris RD, Daniels GH, Porter DM, Belloni DR, Spooner ET, Ernesti MM et al. Multiple endocrine neoplasia 2A due to a unique C609S RET mutation presents with pheochromocytoma and reduced penetrance of medullary thyroid carcinoma. Clinical Endocrinology 200563 676-682. (doi:10.1111/j.1365-2265.2005.02400.x)

8 Toledo RA, Wagner SM, Coutinho FL, Lourenco DM Jr, Azevedo JA, Longuini VC, Reis MT, Siqueira SA, Lucon AM, Tavares MR et al. High penetrance of pheochromocytoma associated with the novel C634Y/Y791F double germline mutation in the RET protooncogene. Journal of Clinical Endocrinology and Metabolism 201095 1318-1327. (doi:10.1210/jc.2009-1355)

9 Machens A, Brauckhoff M, Holzhausen HJ, Thanh PN, Lehnert H \& Dralle H. Codon-specific development of pheochromocytoma in multiple endocrine neoplasia type 2. Journal of Clinical Endocrinology and Metabolism 200590 3999-4003. (doi:10.1210/jc. 2005-0064)

10 Lairmore TC, Ball DW, Baylin SB \& Wells SA Jr. Management of pheochromocytomas in patients with multiple endocrine neoplasia type 2 syndromes. Annals of Surgery 1993217 595-601. (doi:10.1097/00000658-199306000-00001)

11 Rodriguez JM, Balsalobre M, Ponce JL, Rios A, Torregrosa NM, Tebar J \& Parrilla P. Pheochromocytoma in MEN 2A syndrome. Study of 54 patients. World Journal of Surgery 2008 32 2520-2526. (doi:10.1007/s00268-008-9734-2)

12 Sakurai A, Suzuki S, Kosugi S, Okamoto T, Uchino S, Miya A, Imai T, Kaji H, Komoto I, Miura D et al. Multiple endocrine neoplasia type 1 in Japan: establishment and analysis of a multicentre database. Clinical Endocrinology 201276 533-539. (doi:10.1111/j.1365-2265.2011.04227.x)

13 Ito Y, Obara T, Okamoto T, Kanbe M, Tanaka R, Iihara M, Okamoto J, Yamazaki K \& Jibiki K. Efficacy of single-voided urine metanephrine and normetanephrine assay for diagnosing pheochromocytoma. World Journal of Surgery 199822 684-688. (doi:10.1007/s002689900453)

14 Eng C, Clayton D, Schuffenecker I, Lenoir G, Cote G, Gagel RF, van Amstel HK, Lips CJ, Nishisho I, Takai SI et al. The relationship between specific RET proto-oncogene mutations and disease phenotype in multiple endocrine neoplasia type 2 . International RET mutation consortium analysis. Journal of the American Medical Association 1996276 1575-1579. (doi:10.1001/jama.1996. 03540190047028)

15 Quayle FJ, Fialkowski EA, Benveniste R \& Moley JF. Pheochromocytoma penetrance varies by RET mutation in MEN 2A. Surgery 2007142 800-805. (doi:10.1016/j.surg.2007.09.013)

16 Frank-Raue K, Rybicki LA, Erlic Z, Schweizer H, Winter A, Milos I, Toledo SP, Toledo RA, Tavares MR, Alevizaki M et al. Risk profiles and penetrance estimations in multiple endocrine neoplasia type $2 \mathrm{~A}$ caused by germline RET mutations located in exon 10. Human Mutation 201132 51-58. (doi:10.1002/humu.21385)

17 Yip L, Lee JE, Shapiro SE, Waguespack SG, Sherman SI, Hoff AO, Gagel RF, Arens JF \& Evans DB. Surgical management of hereditary pheochromocytoma. Journal of the American College of Surgeons 2004198 525-534. (doi:10.1016/j.jamcollsurg.2003. 12.001)

18 Asari R, Scheuba C, Kaczirek K \& Niederle B. Estimated risk of pheochromocytoma recurrence after adrenal-sparing surgery in patients with multiple endocrine neoplasia type 2A. Archives of Surgery 2006141 1199-1205. (doi:10.1001/archsurg.141. 12.1199)

19 de Graaf JS, Dullaart RP \& Zwierstra RP. Complications after bilateral adrenalectomy for phaeochromocytoma in multiple endocrine neoplasia type 2 - a plea to conserve adrenal function. European Journal of Surgery $1999 \mathbf{1 6 5} 843-846$. (doi:10.1080/ $11024159950189320)$

Received 21 December 2012

Revised version received 13 February 2013

Accepted 14 February 2013 